\title{
Cooperative OFDM Underwater Acoustic Communications with Limited Feedback: Part I
}

\author{
Qian Song \\ Graduate School of Engineering \\ Osaka Prefecture University \\ 1-1 Gakuen-cho, Nakaku \\ Sakai, Osaka, 599-8531, Japan
}

\author{
Mercedes Garcia \\ School of Electrical Engineering \\ Royal Institute of Technology (KTH) \\ SE-100 44 Stockholm, Sweden
}

\begin{abstract}
Cooperative communications have been proved to be a promising technique in next generation wireless communication and network system. Limited feedback is a novel technique that employs several bit of channel state information (CSI) feedback and achieves almost the same performance as perfect feedback. However, literature on cooperative communications and limited feedback in underwater acoustic (UWA) environments is very scarce. Therefore, in this paper, we propose a novel UWA cooperative communication system with limited feedback. Minimum error rate criterion-based optimization model (Part I) will be involved to analyze the performance of the adaptive power allocation based on the proposed system. Limited feedback general procedure and codebook design will be demonstrated. Simulation results will compare the performance of the full CSI feedback, a few bits of feedback and uniform power allocation.
\end{abstract}

\section{General Terms}

Wireless communications and signal processing

\section{Keywords}

Cooperative communications, minimum error rate criterion, power allocation, limited feedback, Lloyd algorithm.

\section{Introduction}

The Underwater acoustic (UWA) communication has been regarded as one of the most challenging wireless communications due to its unique channel properties, such as large Doppler shift, dynamic wind-generated bubbles at sea surface, severe multi-path signal propagation [1-2]. Therefore, how to achieve high data rate and reliable communications in fast time-varying UWA environments is a challenging topic that many scientists have put great effort on it [3-5].

Cooperative communication is a new paradigm that draws from the ideas of using the broadcast nature of the wireless channel to make communicating nodes help each other, of implementing the communication process in a distribution fashion and of gaining the same advantages as those found in MIMO. There are several typical cooperative transmission protocols, such as Amplified- and -Forward (AF) relay, Decode-and-Forward (DF) relay, compress-and-forward (CF) relay. Also, the relaying types can be divided into fixed relaying and adaptive relaying (selective relaying and incremental relaying) [6]. Cooperative communications have been well investigated in the past decade [7-10]. Especially, literature [11-13] focuses on the cooperative communications with limited feedback. However, literature on cooperative communications in UWA environments is scarce [14-20]. [14] analyzed performance of cooperative UWA communications from the aspect of information theory. [15] proposed optimum power allocation strategy and Doppler compensation method for OFDM cooperative underwater networks. [16] proposed a sparse channel estimation method for cooperative UWA communications. [17] proposed a multi-reply and relay selection strategy for cooperative UWA communication systems. [18] studied cooperative diversity technique for UWA wireless communication based on AF relays. [19] proposed a novel wave cooperative transmission scheme, which is specially designed for UWA signal propagations. [20] proposed a receiver design for cooperative MIMO-OFDM UWA channels under Doppler-distorted conditions.

Limited feedback is a novel technique to achieve adaptive communications in wireless environments. It allows only a few bits of feedback that conveys the channel state information (CSI) from the receiver side to the transmitter side, while it can achieve almost the same performance as that of perfect feedback and save resource simultaneously. Therefore, the limited feedback technique has been regarded as a promising technique for the future wireless communications due to the limited communication resource nowadays. Alternatively, the limited feedback technique has been well implemented in Orthogonal Frequency Division Multiplexing (OFDM), Multi-input- and Multi-Output (MIMO), beamforming and other dominant wireless communication issues [21-26]. However, so far only five literature adopted the limited feedback technique in UWA communications [27-31]. To the best of our knowledge, Huang et al. involved the limited feedback technique in UWA communications for the first time.

In this paper, we propose an $\mathrm{AF}$ relay-based cooperative communication system with limited feedback. We will evaluate the adaptive power allocation strategy in terms of minimum error rate criterion. Therein, Lagrange multiplier will be adopted to obtain the optimum solution. In addition, we will introduce the limited feedback general procedure and the Lloyd algorithm-based codebook design. Simulation results will compare the performance of the system with perfect feedback, a few bits of feedback, and non-feedback (uniform allocation).

The remainder of this paper will be organized as follows: Section 2 is the introduction of AF cooperative relay model. Section 3 is the minimum error rate criterion-based power allocation strategy. Section 4 is the demonstration of the limited feedback general procedure and the Lloyd algorithmbased codebook design. Section 5 is the simulation results. Section 6 concludes this paper. 


\section{AF Cooperative Relay Model}

A cooperative communications strategy with two phases is considered for wireless communications and networks. In this paper, we focus on a single relay cooperative scheme, and we take AF relaying scheme as example to demonstrate the cooperative relay UWA communication strategy. Figure 1 shows the schematic description of UWA cooperative communication strategy.

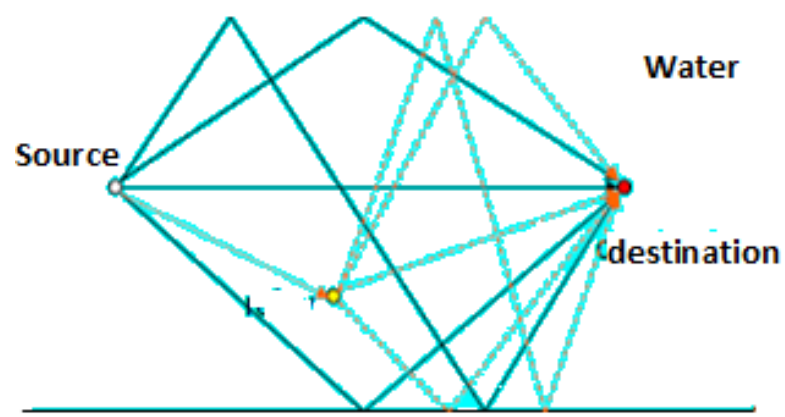

Fig 1: Description of cooperative UWA communication strategies [19]

We assume the cooperative UWA communication system contains a source node $s$, a relay node $r$, and a destination node $d$. The AF cooperative transmission from the source to the destination is accomplished in two phases.

- In Phase 1, the source broadcasts its information to both the destination and the relay at the same time.

- In Phase 2, the relay can help the source by amplifying and forwarding the information to the destination. The received signals at the destination are obtained from source and relay in two different phases.

In Phase 1, the received signals $\mathrm{y}_{\mathrm{s}, \mathrm{d}}$ and $\mathrm{y}_{\mathrm{s}, \mathrm{r}}$ at the destination and relay can be written as

$$
\begin{aligned}
& y_{s, d}=\sqrt{P_{s}} h_{s, d} x+n_{s, d} \\
& y_{s, r}=\sqrt{P_{s}} h_{s, r} x+n_{s, r}
\end{aligned}
$$

where $P_{s}$ is the transmission power of the source, $h_{s, d}$ and $h_{s, r}$ are channel power gain of source-to- destination and sourceto-relay, respectively. $\mathrm{n}_{\mathrm{s}, \mathrm{d}}$ and $\mathrm{n}_{\mathrm{s}, \mathrm{r}}$ are corresponding additive white Gaussian noise with zero-mean and variance $\mathrm{N}_{0}$.

In Phase 2, the received signal $\mathrm{y}_{\mathrm{r}, \mathrm{d}}$ at the destination is given by

$$
\mathrm{y}_{\mathrm{r}, \mathrm{d}}=\frac{\sqrt{\mathrm{P}_{\mathrm{r}} \mathrm{P}_{\mathrm{s}}}}{\sqrt{\mathrm{P}_{\mathrm{r}}\left|\mathrm{h}_{\mathrm{s}, \mathrm{r}}\right|^{2}+\mathrm{N}_{0}}} \mathrm{~h}_{\mathrm{r}, \mathrm{d}} \mathrm{h}_{\mathrm{s}, \mathrm{r}} \mathrm{x}+\mathrm{n}_{\mathrm{r}, \mathrm{d}}^{\prime}
$$

where

$$
\mathrm{n}_{\mathrm{r}, \mathrm{d}}^{\prime}=\frac{\sqrt{\mathrm{P}_{\mathrm{r}}}}{\sqrt{\mathrm{P}_{\mathrm{r}}\left|\mathrm{h}_{\mathrm{s}, \mathrm{r}}\right|^{2}+\mathrm{N}_{0}}} \mathrm{~h}_{\mathrm{r}, \mathrm{d}} \mathrm{n}_{\mathrm{s}, \mathrm{r}}+\mathrm{n}_{\mathrm{r}, \mathrm{d}}
$$

The signal-to-noise ratio (SNR) of the received signal with direct transmission is

$$
\Gamma_{\mathrm{s}, \mathrm{d}}^{\mathrm{DT}}=\frac{\mathrm{P}_{\mathrm{s}}\left|\mathrm{h}_{\mathrm{s}, \mathrm{d}}\right|^{2}}{\mathrm{n}_{\mathrm{s}, \mathrm{d}}{ }^{2}}
$$

The SNR of the received signal at the destination is given by

$$
\Gamma_{\mathrm{s}, \mathrm{r}, \mathrm{d}}^{\mathrm{AF}}=\frac{\frac{\mathrm{P}_{\mathrm{s}}\left|\mathrm{h}_{\mathrm{r}, \mathrm{r}}\right|^{2}}{\mathrm{n}_{\mathrm{s}, \mathrm{r}}} \cdot \frac{\mathrm{P}_{\mathrm{r}}\left|\mathrm{h}_{\mathrm{r}, \mathrm{d}}\right|^{2}}{\mathrm{n}_{\mathrm{r}, \mathrm{d}}^{2}}}{1+\frac{\mathrm{P}_{\mathrm{s}}\left|\mathrm{h}_{\mathrm{s}, \mathrm{r}}\right|^{2}}{\mathrm{n}_{\mathrm{s}, \mathrm{r}}^{2}}+\frac{\mathrm{P}_{\mathrm{r}}\left|\mathrm{h}_{\mathrm{r}, \mathrm{d}}\right|^{2}}{\mathrm{n}_{\mathrm{r}, \mathrm{d}}^{2}}}
$$

Based on Eqs. (5) and (6), and after combine the received signals using maximal ratio combing (MRC), the data rate of the $\mathrm{AF}$ protocol at the receiver side is obtained as

$$
\mathrm{R}_{\mathrm{s}, \mathrm{r}, \mathrm{d}}^{\mathrm{AF}}=\frac{1}{2} \mathrm{Wlog}_{2}\left(1+\Gamma_{\mathrm{s}, \mathrm{d}}^{\mathrm{DT}}+\Gamma_{\mathrm{s}, \mathrm{r}, \mathrm{d}}^{\mathrm{AF}}\right)
$$

where $\mathrm{W}$ is the available bandwidth.

\section{Power Allocation Strategy}

In this paper, we propose a minimum error rate criterionbased power allocation strategy for AF cooperative UWA communications with limited feedback.

We consider the codebook design of power allocation vectors of $\mathrm{w}_{\mathrm{s}}$ (source) and $\mathrm{w}_{\mathrm{r}}$ (relay), which are based on minimizing the average symbol error rate (SER).

Given the same signal constellation is used in each subcarrier, and assuming errors independently occur in each subcarrier, then the probability of SER is bounded by [32]

$$
\mathrm{P}_{\text {VER }} \leq 1-\prod_{\mathrm{i}=1}^{\mathrm{N}}\left(1-\mathrm{N}_{\mathrm{e}} \mathrm{Q}\left(\sqrt{\frac{1}{2} \mathrm{~d}_{\text {min }}^{2} \rho_{\mathrm{i}}}\right)\right)
$$

Where $\mathrm{N}_{\mathrm{e}}$ is the average number of nearest neighbors to a point in any signal constellation $\mathcal{S}, \mathrm{d}_{\min }$ is the minimum distance in $\mathcal{S}, \mathrm{Q}($.$) is the \mathrm{Q}$-function, and $\mathrm{W}$ is the number of subcarriers. Assuming the CSI can be detected and estimated at the receiver side, $\rho_{\mathrm{i}}$ is the received SNR in Eq. (7) .

We define a power allocation vector $\mathbf{w}_{\mathbf{i}}=\left[\mathbf{w}_{\mathbf{s}}, \mathbf{w}_{\mathbf{r}}\right]$, where $\mathrm{P}_{\mathrm{s}}=\mathrm{w}_{\mathrm{s}} \cdot \mathrm{P}_{\text {tot }}$ and $\mathrm{P}_{\mathrm{r}}=\mathrm{w}_{\mathrm{r}} \cdot \mathrm{P}_{\text {tot }} \cdot$ We denote

$$
\mathrm{N}_{\mathrm{e}} \mathrm{Q}\left(\sqrt{\frac{\mathrm{P}_{\mathrm{e}}\left(\mathrm{w}_{\mathrm{si}}, \mathrm{w}_{\mathrm{ri}}, \mathrm{h}_{\mathrm{i}}\right) \triangleq}{2} \mathrm{~d}_{\min }^{2} \underbrace{\gamma\left[\mathrm{w}_{\mathrm{si}}\left|\mathrm{h}_{\mathrm{s}, \mathrm{d}}\right|^{2}+\frac{\mathrm{w}_{\mathrm{si}} \mathrm{w}_{\mathrm{ri}}\left|\mathrm{h}_{\mathrm{s}, \mathrm{r}}\right|^{2}\left|\mathrm{~h}_{\mathrm{r}, \mathrm{d}}\right|^{2}}{1 / \gamma+\mathrm{w}_{\mathrm{si}}\left|\mathrm{h}_{\mathrm{s}, \mathrm{r}}\right|^{2}+\mathrm{w}_{\mathrm{ri}}\left|\mathrm{h}_{\mathrm{r}, \mathrm{d}}\right|^{2}}\right]}_{\mu_{\mathrm{i}}}}\right)
$$

where $\gamma=\mathrm{P}_{\text {tot }} / \mathrm{N}_{0}$, the optimization problem is formally expressed as

$$
\begin{aligned}
& \min _{\mathrm{w}_{s}, \mathrm{w}_{\mathbf{r}}} 1-\prod_{\mathrm{i}=1}^{\mathrm{N}}\left(1-\mathrm{P}_{\mathrm{e}}\left(\mathrm{w}_{\mathrm{si}}, \mathrm{w}_{\mathrm{ri}}, \mathrm{h}_{\mathrm{k}}\right)\right) \\
& \text { s.t. } 1^{\mathrm{T}} \mathrm{w}_{\mathrm{s}}+1^{\mathrm{T}} \mathrm{w}_{\mathrm{r}}=1 \\
& \mathrm{w}_{\mathrm{s}} \geq 0, \mathrm{w}_{\mathrm{r}} \geq 0,
\end{aligned}
$$

We employ the Lagrange multiplier method and KKT conditions to find out the solution of (10)

We obtain the optimum power allocation vectors as 


$$
\begin{aligned}
& \mathrm{w}_{\mathrm{si}}=\frac{\mathrm{a}_{\mathrm{si}}^{2}}{\sum_{\mathrm{i}=1}^{\mathrm{N}} \llbracket\left(\left(\mathrm{a}_{\mathrm{si}}^{2}+\mathrm{a}_{\mathrm{ri}}^{2}\right) \rrbracket\right)} \\
& \mathrm{w}_{\mathrm{ri}}=\frac{\mathrm{a}_{\mathrm{ri}}^{2}}{\sum_{\mathrm{i}=1}^{\mathrm{N}} \llbracket\left(\left(\mathrm{a}_{\mathrm{si}}^{2}+\mathrm{a}_{\mathrm{ri}}^{2}\right) \rrbracket\right)}
\end{aligned}
$$

where

$$
\begin{aligned}
& \mathrm{a}_{\mathrm{si}}=\sqrt{\mathrm{w}_{\mathrm{si}}} \frac{\partial \mathrm{P}_{\mathrm{e}}\left(\mathrm{w}_{\mathrm{si}}, \mathrm{w}_{\mathrm{ri}}\right)}{\partial \mathrm{w}_{\mathrm{si}}}\left(1-\mathrm{P}_{\mathrm{e}}\left(\mathrm{w}_{\mathrm{si}}, \mathrm{w}_{\mathrm{ri}}\right)\right)^{-1} \\
& \mathrm{a}_{\mathrm{ri}}=\sqrt{\mathrm{w}_{\mathrm{si}}} \frac{\partial \mathrm{P}_{\mathrm{e}}\left(\mathrm{w}_{\mathrm{si}}, \mathrm{w}_{\mathrm{ri}}\right)}{\partial \mathrm{w}_{\mathrm{ri}}}\left(1-\mathrm{P}_{\mathrm{e}}\left(\mathrm{w}_{\mathrm{si}}, \mathrm{w}_{\mathrm{ri}}\right)\right)^{-1}
\end{aligned}
$$

For high SNR, (e.g., $\gamma \rightarrow \infty), Q\left(\sqrt{\frac{1}{2} d_{\min }^{2} \gamma \mu_{\mathrm{i}}}\right)$

approaches to zero [33]. By substituting Eqs. (13),

(14), and (9) into (11), we can obtain the following

equation:

$$
\begin{aligned}
& 1=\frac{e^{-\frac{1}{2} d_{\min }^{2} \gamma \mu_{\mathrm{i}}}}{\mu_{\mathrm{i}}}\left(\frac{\partial \mu_{\mathrm{i}}}{\partial \mathrm{w}_{\mathrm{si}}}\right)^{2} \times \\
& \quad\left(\sum_{\mathrm{j}=1}^{\mathrm{N}} \mathrm{e}^{-\frac{\mathrm{d}_{\min }^{2} \gamma \mu_{\mathrm{j}}}{2}}\left[\frac{\mathrm{w}_{\mathrm{sj}}}{\mu_{\mathrm{i}}}\left(\frac{\partial \mu_{\mathrm{i}}}{\partial \mathrm{w}_{\mathrm{si}}}\right)^{2}+\frac{\mathrm{w}_{\mathrm{rj}}}{\mu_{\mathrm{j}}}\left(\frac{\partial \mu_{\mathrm{j}}}{\partial \mathrm{w}_{\mathrm{rj}}}\right)^{2}\right]^{-1}\right.
\end{aligned}
$$

Similarly, we can obtain the solution for $\mathrm{w}_{\mathrm{rj}}$ based on the same method as follow:

$$
\begin{aligned}
& 1=\frac{\mathrm{e}^{-\frac{1}{2} \mathrm{~d}_{\min }^{2} \gamma \mu_{\mathrm{i}}}}{\mu_{\mathrm{i}}}\left(\frac{\partial \mu_{\mathrm{i}}}{\partial \mathrm{w}_{\mathrm{ri}}}\right)^{2} \times \\
& \quad\left(\sum_{\mathrm{j}=1}^{\mathrm{N}} \mathrm{e}^{-\frac{\mathrm{d}_{\min }^{2} \gamma \mu_{\mathrm{j}}}{2}}\left[\frac{\mathrm{w}_{\mathrm{sj}}}{\mu_{\mathrm{i}}}\left(\frac{\partial \mu_{\mathrm{i}}}{\partial \mathrm{w}_{\mathrm{si}}}\right)^{2}+\frac{\mathrm{w}_{\mathrm{rj}}}{\mu_{\mathrm{j}}}\left(\frac{\partial \mu_{\mathrm{j}}}{\partial \mathrm{w}_{\mathrm{rj}}}\right)^{2}\right]^{-1}\right.
\end{aligned}
$$

By comparing Eqs. (15) and (16), we conclude that

$$
\lim _{\gamma \rightarrow \infty} \mu_{\mathrm{i}}=\lim _{\gamma \rightarrow \infty} \mu_{\mathrm{j}}=\text { const }
$$

for all $i, j$.

In order to simplify the solution of our optimization problem, we impose another condition: $w_{s i}=w_{r i}$ for $\mathrm{i}=1, \ldots, \mathrm{N}$.

By solving the Eqs. (10) and (17) together, we obtain $\mathrm{w}_{\mathrm{si}}=\mathrm{w}_{\mathrm{ri}}=$ const $\times(\underbrace{\left|\mathrm{h}_{\mathrm{r}, \mathrm{d}}\right|^{2}+\frac{\left|\mathrm{h}_{\mathrm{s}, \mathrm{r}}\right|^{2}\left|\mathrm{~h}_{\mathrm{r}, \mathrm{d}}\right|^{2}}{\left|\mathrm{~h}_{\mathrm{r}, \mathrm{r}}\right|^{2}+\left|\mathrm{h}_{\mathrm{r}}\right|^{2}}}_{\mathcal{H}_{\mathrm{i}}})^{-1}$

After inserting Eq. (25) into Eq. (10), we can obtain the value of const. Therefore, the final results can be shown as

$$
\mathrm{w}_{\mathrm{si}}=\mathrm{w}_{\mathrm{ri}}=\frac{\mathcal{H}_{\mathrm{i}}^{-1}}{2 \sum_{\mathrm{j}=1}^{\mathrm{N}} \mathcal{H}_{\mathrm{i}}^{-1}}
$$

and

$$
\mathrm{w}_{\mathrm{si}}=\mathrm{w}_{\mathrm{ri}}=\frac{\mathcal{H}_{\mathrm{i}}^{-1}}{\sum_{\mathrm{j}=1}^{\mathrm{N}} \mathcal{H}_{\mathrm{i}}^{-1}}
$$

\section{Lloyd Algorithm-Based Limited Feedback Procedure}

Since we have obtained the optimal solution of power allocation in Eqs. (19) and (20), we design a finite codebook $\mathcal{W}=\left\{\left(\mathbf{w}_{\mathbf{s}}, \mathbf{w}_{\mathbf{r}}\right)_{1}, \ldots,\left(\mathbf{w}_{\mathbf{s}}, \mathbf{w}_{\mathbf{r}}\right)_{\mathbf{N}}\right\}$, where $\mathrm{N}$ is the size of the codebook. In the limited feedback procedure, and the optimal codebook is defined as $\mathbf{w}_{\mathbf{o p t}}$. At first, the CSI will be quantized into $\mathrm{H}=2^{\mathrm{M}}$ parts, where $\mathrm{M}$ is the number of feedback bits. After selecting the optimal power allocation vector, its index will be fed back from the destination to the transmitter and relay sides, where the designed codebook is equipped in transmitter, relay node and destination.

In order to apply the Lloyd algorithm, we define an error distance function to measure the average distortion. The average distortion function $\mathrm{D}_{\mathrm{SER}}(\mathcal{W})$ is defined as

$$
\mathrm{D}_{\mathrm{SER}}(\mathcal{W})=\mathrm{E}_{\mathrm{h}}\left[\mathrm{C}^{\prime}\left(\mathbf{w}_{\mathbf{o p t}} \mid \mathbf{h}\right)-\min _{0 \leq \mathrm{i} \leq \mathrm{N}} \mathrm{C}^{\prime}\left(\mathbf{w}_{\mathbf{i}} \mid \mathbf{h}\right)\right]
$$

Now, the Lloyd algorithm-based limited feedback procedure can be described as follows:

1. First, randomly generate a codebook of power allocation vectors $\mathcal{W}_{0}=\left\{\mathrm{w}_{1}^{0}, \mathrm{w}_{2}^{0}, \ldots, \mathrm{w}_{\mathrm{N}}^{0}\right\}$ and set $\mathrm{i}=1$.

2. Divide the set of possible channel vectors into $\mathrm{H}$ quantization regions with kth region defined as

$$
\begin{gathered}
\mathcal{C}_{\mathrm{k}}=\left\{\mathbf{H}=\left\langle\mathcal{H}_{1},,, \mathcal{H}_{\mathrm{N}}\right\rangle \mid\left(\mathrm{w}_{\mathrm{k}}^{\mathrm{i}-1}\right)^{\mathrm{T}} \mathrm{w}_{\mathrm{s}} \geq\left(\mathrm{w}_{\mathrm{l}}^{\mathrm{i}-1}\right)^{\mathrm{T}} \mathrm{w}_{\mathrm{s}}\right. \\
\forall \mathrm{l} \neq \mathrm{k}\}
\end{gathered}
$$

3. Construct a new codebook

$$
\mathcal{W}_{\mathrm{i}}^{\mathrm{k}}=\arg \min _{\mathbf{w}} \mathrm{E}_{\mathrm{h} \in \mathrm{C}_{\mathrm{k}}}\left[\mathrm{C}^{\prime}(\mathbf{w} \mid \mathbf{h})\right]
$$

Generally speaking, the distortion can be expressed and bounded as

$$
\mathrm{E}\left[\min _{\mathrm{w} \in \mathcal{W}}\left(\min _{1 \leq \mathrm{i} \leq \mathrm{N}} \mathcal{H}_{\mathrm{i}}\left(\mathrm{w}_{\mathrm{si}}-\mathrm{w}_{\mathrm{i}}\right)^{2}\right] \leq\right.
$$

$\mathrm{NE}\left[\|\mathbf{H}\|_{2}^{2}\right] \mathrm{E}\left[\min _{\mathbf{w} \in \mathcal{W}}\left(2-2 \mathbf{w}^{\mathrm{T}} \mathbf{w}_{\mathrm{s}}\right)\right]$ 
Where $\mathbf{w}=\left[\mathrm{w}_{1}, \ldots, \mathrm{w}_{\mathrm{N}}\right]$ and $\mathrm{H}=\left[\mathcal{H}_{1}, \ldots, \mathcal{H}_{\mathrm{N}}\right]$. In order to minimize the general distortion function, equivalently the following function can be minimized:

$$
\mathrm{D}_{\mathrm{SER}}(\mathcal{W})=\mathrm{E}\left[\min _{\mathbf{w} \in \mathcal{W}}\left(2-2 \mathbf{w}^{\mathrm{T}} \mathbf{w}_{\mathrm{s}}\right)\right]
$$

4. If $\mathrm{D}_{\mathrm{SER}}\left(\mathcal{W}_{\mathrm{i}}\right)-\mathrm{D}_{\mathrm{SER}}\left(\mathcal{W}_{\mathrm{i}-1}\right)<0$, set $i=i+1$, and go back to Step 2 . Otherwise, set $\mathcal{W}=\mathcal{W}_{\mathrm{i}}$ and stop iteration.

\section{Simulation Results}

We adopt the Bellhop algorithm [34] to simulate the underwater acoustic channel impulse, the main parameter settings are listed as follows: transmit distance: 1200meters, source and destination depths: 5 meters; relay node depth 6meters; water depth: 30meters; transmit frequency: $15 \mathrm{kHz}$; bandwidth: $6 \mathrm{kHz}$; number of subcarriers: 128 ; subcarrier space: $46.8 \mathrm{~Hz}$; symbol duration: $21.3 \mathrm{~ms}$.

Figure 2 shows simulation results of performance of $\mathrm{AF}$ cooperative relay-aided transmission with non-feedback, perfect feedback, 1-bit feedback, 2-bit feedback and 3-bit feedback, respectively. Results indicate that by employing the Lloyd algorithm-based limited feedback procedure, several bits of feedback can achieve almost the same performance as that of traditional perfect feedback.

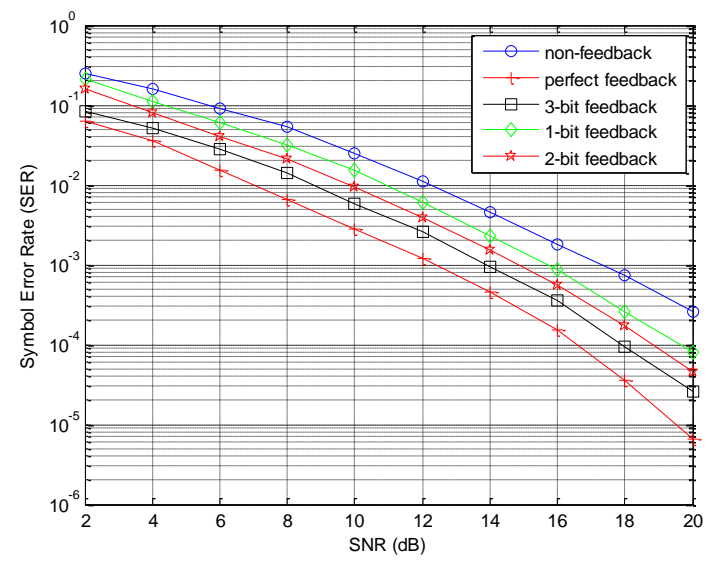

Figure 2. Simulation results of performance of $\mathrm{AF}$ cooperative relay-aided transmission with different feedback levels.

\section{Conclusion}

Cooperative relay-aided communications are novel for the underwater environments. This paper proposed a limited feedback-based UWA cooperative transmission system design. Simulation results showed our proposed system is a promising technique to be deployed for higher performance than tradition perfect feedback-based systems.

\section{REFERENCES}

[1] T. C. Yang, "Properties of underwater acoustic communication channels in shallow water", J. Acoust. Soc. Am., vol. 131, no. 1, pp.129-145, Jan. 2012
[2] A. C. Singer, J. K. Nelson and S. S. Kozat, "Signal Processing for Underwater Acoustic Communications", IEEE Communications Magazine, pp.90-96, Jan. 2009

[3] A. song and M. Badiey, "Time reversal multipleinput/multiple-output acoustic communication enhanced by parallel interference cancellation", J. Acoust. Soc. Am., vol. 131, no. 1, pp. 281-291, 2012

[4] X. Huang and V. B. Lawrence, "OFDM with pilot Aided Channel Estimation for time-varying shallow water acoustic channels", IEEE CMC conference, pp. 442-446, April 2010

[5] K. Tuy, D. Fertonani, T. Duman, M. Stojanovic, J. Proakis and P. Hursky, "Mitigation of intercarrier interference for OFDM over time-varying underwater acoustic channels", IEEE Journal of Oceanic Engineering, vol. 36, no. 2, April 2011, pp. 156-171

[6] K. J. R. Liu, A. K. Sadek, W. Su and A. Kwasinski, "Cooperative Communications and Networking", Cambridge publisher, 2009

[7] A. S. Ibrahim, A. K. Sadek, W. Su and K. J. R. Liu, "Cooperative communications with relay selection: when to cooperate and whom to cooperate with?", IEEE Trans. on Wireless Comm., vol. 7, no. 7, pp. 2814-2817, July 2008

[8] P. Zhang, Z. Xu, F. Wang, X. Xie and L. Tu, "A relay assignment algorithm with interference mitigation for cooperative communication", IEEE WCNC conference, pp. 1-6, 2009

[9] R. Chen, S. Leng and X. Huang. "A joint resource allocation algorithm for cooperative communications", ICACC conference, pp. 311-315, 2011

[10] J. Huang, Z. Han, M. Chiang, and H. V. Poor, “ Auctionbased resource allocation for cooperative communications", vol. 26, no. 7, IEEE Journal on Selected Areas in Commuinications, vol. 26, no. 7, pp. 1226-1237, Sept. 2008

[11] Y. Liu, W. Chen and X. Huang, "Capacity Based Adaptive Power Allocation for the OFDM Relay Networks with Limited Feedback", IEEE ICC conference, pp. 1-5, 2011

[12] J. M. Paredes, B. H. Khalaj, and A. B. Gershman, "Cooperative Transmission for wireless relay networks using limited feedback", IEEE Trans. on Signal Processing, vol. 58, no. 7, pp. 3828-3841, July 2010

[13] R. Bhagavatual and R. W. Heath, "Predictive limited feedback for cooperative transmission", ASILOMAR Conference, pp. 1237-1241, 2010

[14] S. Al-Dharrab, M. Uysal. Information Theoretic Performance of Cooperative Underwater Acoustic Communications. IEEE $22^{\text {nd }}$ PIMRC conference, $p$. 1562-1566, 2011

[15] S. Yerramalli, U. Mitra. Optimal Power Allocation and Doppler Compensation in Cooperative Underwater Networks Using OFDM. IEEE Oceans Conference, pp. $1-6,2009$

[16] N. Richard, U.Mitra. Sparse Channel Estimation for Cooperative Underwater Communications: A Structured Multichannel Approach. IEEE ICASSP Conference, pp. 5300-5303, 2008 
[17] B. Karakaya, M. O. Hasna, M. Uysal, T. M. Duman, A. Ghrayeb. Relay Selection for Cooperative Underwater Acoustic Communication Systems. IEEE $19^{\text {th }}$ ICT Conference, pp.1-6, 2012

[18] J. Han, H. Ju. K. Kim, S. Chun and K. Dho. A Study on the Cooperative Diversity Technique with Amplify and Forward for Underwater Wireless Communication. IEEE Oceans Conference, pp. 1-3. 2008

[19] Z. Han, Y. L. Sun, H. Shi. Cooperative Transmission for Underwater Acoustic Communications. IEEE ICC Conference. pp. 2028-2032, 2008

[20] K. Tu, T. M. Duman, J. G. Proakis and M. Stojanovic. Cooperative MIMO-OFDM Communications: Receiver Design for Doppler-Distorted Underwater Acoustic Channels. ASILOMAR Conference, pp. 1335-1339, 2010

[21] N. Khaled, B. Mondal, G. Leus, R. W. Heath, Jr. and F. Petre, "Interpolation-based multi-mode precoding for MIMO-OFDM systems with limited feedback," IEEE Trans. Wireless Comm., vol. 6, no. 3, pp. 1003-1013, March 2007

[22] J. S. Kim, H. Kim, and K. B. Lee, "Limited feedback signaling for MIMo broadcast channels", in Proc. IEEE Int. Workshop on signal Proc. Adv. Wireless Commun., June 2005, pp. 855-859

[23] S. A. Jafar and S. Srinivasa, "On the optimality of beamforming with quantized feedback", IEEE Trans. Commun., vol. 55, no. 12, pp. 2288-2302, Dec. 2007

[24] R. Agarwal, R. Vannithamby, and J. Cioffi, "Optimal allocation of feedback bits for downlink OFDMA systems", in Proc. IEEE Int. Symp. Info. Th., July 2008, pp.1686-1690

[25] H. Chae, Y. Kim, J. H. Yang, B. Ihm and D. K. Kim, "Multimode random beamforming for multiuser downlink MIMO system with limited feedback", in Proc. IEEE Veh. Technol. Conf., May 2008, pp. 837-841
[26] C. B. Chae, D. Mazzarese, N. Jindal and R. W. Heath, "Coordinated beamforming with limited feedback in the MIMO broadcast channel", IEEE J. Select. Areas. Commun., vol. 26, no. 8, Oct. 2008

[27] X. Huang. Capacity Criterion-Based Power Loading for Underwater Acoustic OFDM System with Limited Feedback. IEEE WCNIS, pp. 54-58, 2010

[28] X. Huang and V. B. Lawrence. Bandwidth-Efficient Bit and Power Loading for Underwater Acoustic OFDM Communication System with Limited Feedback. IEEE $73^{\text {rd }}$ VTC Conference, pp.1-5, 2011

[29] X. Huang and V. B. Lawrence. Capacity Criterion-Based Bit and Power Loading for Shallow Water Acoustic OFDM System with Limited Feedback . IEEE $73^{\text {rd }}$ VTC Conference, pp. 1-5, 2011

[30] X. Huang and V. B. Lawrence. Effect of wind-generated bubbles on OFDM power loading for time-varying shallow water acoustic channels with limited feedback IEEE Oceans Conference, pp.1-6, 2011

[31] A. Radosevic, T. M. Duman, J. G. Proakis. M Stojanovic. Adaptive OFDM for Underwater Acoustic Channels with Limited Feedback. ASILOMAR Conference, pp.975-980, 2011

[32] D. J. Love and R. W. Heath, "OFDM power loading using limited feedback", IEEE Trans. Veh. Technol. Vol. 54, no. 5, pp. 1773-1780, Sept. 2005

[33] L. Goldfeld, V. Lyandres and D. Wulich, "Minimum BER power loading for OFDM in fading channel", IEEE Trans. Commun., vol. 50, no. 11, pp. 1729-1733, Nov. 2012

[34] http://oalib.hlsresearch.com/Rays/index.html 